\title{
Código de Endereçamento Postal (CEP), um obstáculo aos Dados Abertos no Brasil
}

\author{
Postal Adress Code (CEP), an obstacle to Open Data in Brazil \\ Código de direccionamiento postal (CEP), un obstáculo a los Datos \\ Abiertos en Brasil
}

\author{
Ana Maria de Almeida Ribeiro | ribeiro@acd.ufrj.br \\ Universidade Federal do Rio de Janeiro. Rio de Janeiro, Brasil. \\ Universidade de Brasília. Brasília, DF, Brasil. \\ Eliane Braga de Oliveira | elianebo@unb.br \\ Universidade de Brasília. Brasília, DF, Brasil.
}

\section{Resumo}

Esta comunicação apresenta uma análise da apropriação do Código de Endereçamento Postal (CEP) pela Empresa Brasileira de Correios e Telégrafo, transformando uma informação pública de acesso gratuito em produto comercializado. O CEP foi desenvolvido em substituição às Zonas Postais (ZP) ou Zonas de Correio (ZC), criadas pelo então Departamento de Correios e Telégrafos (DCT) que é transformado em empresa pública em 1967 durante a Ditadura Militar. Através de pedidos de informação registrados no Serviço de Informação ao Cidadão, instituído pela Lei de Acesso à Informação em 2012, e decisões da Controladoria Geral da União e do Supremo Tribunal Federal, avaliamos os argumentos e a sustentação da não inclusão do CEP nos Dados Abertos do governo federal. A abordagem é qualitativa e as técnicas utilizadas para a coleta de dados foram a pesquisa bibliográfica, análise de documentos públicos, publicações e legislações relativas ao tema.

Palavras-chave: Código de Endereçamento Postal. Empresa Brasileira de Correios e Telégrafos. Transparência Pública. Lei de Acesso à Informação. Dados Abertos. 


\section{Abstract}

This communication presents an analysis of the appropriation of the Postal Address Code (CEP) by the Brazilian Post and Telegraph Company, transforming public information of free access into commercialized product. The CEP was developed to replace Postal Zones (ZP) or Zones de Correo (ZC), created by the then Department of Posts and Telegraphs (DCT) that was transformed into a public company in 1967 during the Military Dictatorship. Through requests for information registered in the Citizen Information Service, instituted by the Law on Access to Information in 2012, and decisions of the General Union Comptroller and the Federal Supreme Court, we evaluate the arguments and support the non-inclusion of CEP in Open Data of the federal government. The approach is qualitative and the techniques used for the collection of data were bibliographic research, analysis of public documents, publications and legislation related to the subject.

Keywords: Postal Adress Code. Brazilian Postal and Telegraph Company. Public Transparency. Law of Access to Information. Open Data.

\section{Resumen}

Esta comunicación presenta un análisis de la apropiación del Código de Direccionamiento Postal (CEP) por la Empresa Brasileña de Correos y Telégrafo, transformando una información pública de acceso gratuito en producto comercializado. El CEP fue desarrollado en sustitución de las Zonas Postales (ZP) o Zonas de Correo (ZC), creadas por el entonces Departamento de Correos y Telégrafos (DCT) que es transformado en empresa pública en 1967 durante la Dictadura Militar. A través de solicitudes de información registradas en el Servicio de Información al Ciudadano, instituido por la Ley de Acceso a la Información en 2012, y decisiones de la Contraloría General de la Unión y del Supremo Tribunal Federal, evaluamos los argumentos y la sustentación de la no inclusión del CEP en los Datos Abiertos del gobierno federal. El enfoque es cualitativo y las técnicas utilizadas para la recolección de datos fueron la investigación bibliográfica, análisis de documentos públicos, publicaciones y legislaciones relativas al tema.

Palabras clave: Código de Direccionamiento Postal. Empresa Brasileña de Correos y Telégrafos. Transparencia Pública. Ley de acceso a la información. Datos Abiertos.

\section{Introdução}

O Código de Endereçamento Postal (CEP) foi criado, em 1971, pela Empresa Brasileira de Correios e Telégrafo (ECT) ${ }^{\mathrm{i}}$ com objetivo principal, segundo a empresa ${ }^{1}$, de orientar e acelerar o encaminhamento, o tratamento e a distribuição de objetos postados nos Correios. Este processo é possível pela sua formatação que obedece a lógica da organização político-administrativa brasileira identificando o estado, o município e a região, e nestes, o bairro e a rua, quando se tratam de grandes cidades. Esta identificação foi desenvolvida em substituição às Zonas Postais (ZP) ou Zonas de Correio (ZC), criadas pelo então Departamento de Correios e Telégrafos (DCT) vinculado ao Ministério de Viação e Obras Públicas² ${ }^{2}$ que foi transformado em Empresa Pública pelo Decreto-Lei no 509/1967, durante a Ditadura Militar.

A divulgação do CEP ao público ocorreu pela primeira vez em 1971, com a publicação do Guia Postal Brasileiro ${ }^{1}$. A ECT considera vital o uso do CEP, que é utilizado em todo o território nacional, para execução de sua prestação de serviço, sendo obrigatório informar o código para o envio de qualquer objeto através da empresa. Além disso, qualquer cidadão usuário de sistemas eletrônicos, que exijam o preenchimento de cadastro, sabe que sem a inclusão do CEP o mesmo não é concluído, sendo informação obrigatória na maioria dos sites. A própria empresa em sua página na internet reforça a importância para a execução de sua própria atividade, o correto uso da informação. "O uso adequado do CEP é imprescindível para que os Correios possam tratar com rapidez os objetos que lhe são confiados, racionalizando os métodos de separação dos objetos ao permitir o tratamento mecanizado (triagem, encaminhamento e distribuição) com

i No artigo usaremos os termos "ECT" e "Correios" para identificar a Empresa Brasileira de Correios e Telégrafos, que já adotou a sigla EBCT, depois ECT e, desde 2014 vem utilizando a marca Correios. 
a utilização de equipamentos eletrônicos de triagem. Com o CEP inadequado ou errado, as correspondências e encomendas demandam mais tempo para serem devidamente separadas e entregues. [....]."”.

Entretanto, o acesso à base de dados do CEP é negado aos cidadãos.

A implantação da Lei de Acesso à Informação (LAI) no Brasil, em 16 de maio de 2012, abrangeu todos os poderes da República (executivo, legislativo e judiciário) e todos os três níveis de governo (federal, estadual e municipal). A LAI iniciou sua implantação no poder executivo federal com a utilização de uma ferramenta tecnológica, através de um sistema de âmbito nacional, o e-SIC, monitorado pela Controladoria Geral da União (CGU)ii. O sistema é centralizado para tratamento de pedidos de acesso à informação no âmbito do Poder Executivo Federal, onde o cidadão acompanha sua tramitação e respostas.

A implantação da LAI nas empresas estatais, estruturas da administração pública indireta, apresenta um diferencial com relação aos demais órgãos do poder executivo federal: seu regime jurídico diferenciado - são instituições públicas regidas pelo direito privado. Como empresas estatais, estão sujeitas aos controles públicos e comprometidas com objetivos coletivos, podendo ser prestadoras de serviços públicos, ou exploradoras de atividades econômicas.

O Supremo Tribunal Federal (STF), nos debates a que tem sido chamado a se manifestar sobre as empresas estatais, as caracterizam como empresas submetidas a um regime híbrido. "Embora a rigor, as denominadas 'empresas estatais' ostentem a natureza jurídica de direito privado, elas se submetem a regime híbrido, ou seja, sujeitam-se a um conjunto de limitações que têm por escopo a realização do interesse público. Em outras palavras, no caso dessas entidades, ocorre uma derrogação parcial das normas de direito privado em favor de certas regras de direito público. "4 .

Após a implantação da LAI na ECT, cidadãos que registraram pedidos de informação, solicitando acesso à base de dados do CEP, tiveram o pedido negado pela ECT e recorreram da decisão ${ }^{5}$. Através da transparência ativaiii disponibilizada pela CGU, é possível realizar as buscas inserindo palavras-chaves ou por filtros específicos. Desse modo identificamos alguns desses pedidos.

A lista de CEP já esteve disponibilizada em formato impresso, em todas as agências e locais públicos para livre acesso, em meio eletrônico (disquetes) e a base de dados disponibilizada, gratuitamente, na página na internet dos Correios, em formato TXT, como identificado nos arquivos pesquisados, assim como presente na memória dos brasileiros. Entretanto, a ECT criou, nos anos 2000, o Diretório Nacional de Endereços $(\mathrm{e}-\mathrm{DNE})^{6}$, passou a comercializar essa informação, por valores que variam entre mil a dois mil e quinhentos reais $^{\text {iv }}$, e informa que é um produto, negando assim o acesso à esta base de dados. Os cidadãos apenas têm acesso, na internet, a consultar individualmente cada CEP, através do "Busca CEP-Endereços". A negativa de acesso à base de dados, após a LAI, ensejou recursos à CGU, instância recursal, e os pareceres publicados abrem o debate sobre o acesso público desta informação.

A presente comunicação analisa a base de dados do CEP e apresenta o seu caráter público e os motivos que impedem ser uma informação em Dados Abertos. O objetivo geral é compreender como o estatuto jurídico da ECT, empresa pública de direito privado, influencia na aplicação da LAI no Brasil, ao transformar uma informação que foi pública em produto comercial. O monopólio postal e a determinação constitucional da União em manter o serviço postalv e o correio aéreo nacional, contrastam com a decisão

\footnotetext{
ii A Presidenta Dilma foi afastada do cargo dia 12/05/2016 e neste mesmo dia o Vice-Presidente Michel Temer ao assumir temporariamente, por 180 dias, publicou a Medida Provisória (MP) 176, que extinguiu a CGU e criou o Ministério da Transparência, Fiscalização e Controle. O impedimento definitivo ocorreu em 31/08/2016 e a MP convertida em Lei $n^{\circ} 13.341$. Entretanto, optamos por continuar a utilizar, em toda a pesquisa, a sigla CGU como referência ao órgão de controle.

iii Através do Busca de Pedidos e Respostas é possível acompanhar os temas já solicitados e respondidos pelos órgãos públicos http://www.acessoainformacao.gov.br/assuntos/busca-de-pedidos-e-respostas

iv Os valores cobrados estão disponíveis na página da ECT <https://www.correios.com.br/para-voce/consultas-e-solicitacoes/ precos-e-prazos/servicos-nacionais_pasta/e-dne>

v Competências da União estabelecidas no artigo 21 da Constituição Federal, no inciso X.
} 
de negativa de promover a publicação de dados contidos nas bases de dados do CEP. Como objetivos específicos, apresentamos uma análise do Estado brasileiro que aprova a criação da ECT, contextualizando o momento histórico e político do Brasil de criação da ECT (União é 100\% acionista) e responsável pelo dever constitucional de manter o serviço postal no Brasil e na análise das respostas sobre o CEP no SICECT, objeto de recursos na CGU em que a Lei Postal sobrepõe a Lei de Acesso à Informação.

\section{Metodologia}

A abordagem aplicada a essa pesquisa é a qualitativa e o método de interpretação do contexto histórico se constitui como fundamento de ação política na construção do conhecimento. Foi adotada a concepção construtivista social, em que procuramos entender o mundo em que vivemos e trabalhamos na busca de compreender os ambientes históricos e culturais dos sujeitos analisados7 ${ }^{7}$ As técnicas utilizadas para a coleta de dados foram a pesquisa bibliográfica, análise de documentos públicos, publicações e legislações relativas ao tema.

\section{De Informação Pública à Produto Comercializado}

Em 20 de março de 1969, um pouco mais de dois anos após a publicação do Decreto-Lei 200/67 (DL200), e cinco anos do golpe militar, os militares publicaram o Decreto-Lei 509 (DL509), que dispõe sobre a transformação do Departamento dos Correios e Telégrafos (DCT) em empresa pública. Logo no artigo $1^{\circ}$ estabelece a transformação do DCT em Empresa Brasileira de Correios e Telégrafos (ECT) nos termos do item II do art. $5^{\circ}$ do DL20o, que define empresa pública.

Outro destaque importante, e objeto de grandes debates jurídicos, é o artigo que estabelece o monopólio postal "Art. $2^{\mathrm{O}}$ - À ECT compete: I - executar e controlar, em regime de monopólio, os serviços postais em todo o território nacional; $[\ldots]^{8}$ ", garantindo assim, sua primazia no mercado de serviço postal.

Da transformação do DCT na empresa pública de direito privado em 1967 - a ECT, se passaram 11 anos até que uma lei regulamentasse o serviço postal no Brasil. Em 1978 é publicada a Lei nº 6.538 - a Lei Postal, esta lei vem, então, para reforçar o papel de exclusividade da ECT no mercado postal num momento em que a violação do monopólio começava a ameaçar os negócios da empresa ${ }^{9}$. Seu artigo 15 determina a obrigação de manter nas unidades de atendimento, à disposição dos usuários a lista de códigos de endereçamento postal, o que foi cumprido à risca por muitos anos. Entretanto, a lista não é mais impressa há muitos anos.

Pelo texto da lei é a lista, hoje compreendida como base de dados, que deve estar à disposição dos usuários e não um código específico. "Art. 15 - A empresa exploradora do serviço postal é obrigada a manter, em suas unidades de atendimento, à disposição dos usuários, a lista dos códigos de endereçamento postal. $\S 1^{0}$ - A edição de listas dos códigos de endereçamento postal é da competência exclusiva da empresa exploradora do serviço postal, que pode contratá-la com terceiros, bem como autorizar sua reprodução total ou parcial. $\S 2^{0}$ - A edição ou reprodução total ou parcial da lista de endereçamento postal fora das condições regulamentares, sem expressa autorização da empresa exploradora do serviço postal, sujeita quem a efetue à busca e apreensão, dos exemplares e documentos a eles pertinentes, além da indenização correspondente ao valor da publicidade neles inserta. $\S 3^{\circ}$ - É facultada a edição de lista de endereçamento postal sem finalidade comercial e de distribuição gratuita, conforme disposto em regulamento. ${ }^{10}$ "

$\mathrm{O}$ artigo $8^{\circ}$ define as atividades correlatas ao serviço postal, em que prevê a venda de listas de código de endereçamento, e tem sido utilizado pela empresa como justificativa para a sua comercialização, e para negativa do acesso ao banco de dados e sua disponibilização em Dados Abertos. O parágrafo $3^{\circ}$ do artigo 15 que faculta a edição da lista de endereçamento postal sem finalidade comercial e de distribuição gratuita, vem sendo ignorado. "Art. $8^{\circ}$ - São atividades correlatas ao serviço postal: I - venda de selos, peças filatélicas, 
cupões resposta internacionais, impressos e papéis para correspondência; II - venda de publicações divulgando regulamentos, normas, tarifas, listas de código de endereçamento e outros assuntos referentes ao serviço postal. III - exploração de publicidade comercial em objetos correspondência. Parágrafo único A inserção de propaganda e a comercialização de publicidade nos formulários de uso no serviço postal, bem como nas listas de código de endereçamento postal, é privativa da empresa exploradora do serviço postal." ${ }^{0}$

É necessário destacar que a legislação citada é de 1978 e, portanto, trata da disponibilização da informação impressa o que significava, para a época, custo adicional com aquisição de papel, contratação de gráfica etc. Cenário em que se justificava a previsão de inserção e comercialização de propaganda nas listas, para auto custear a publicação.

Similarmente, a Lei 9.472/97, de 16 de julho, dispõe sobre a organização dos serviços de telecomunicações e outras questões ${ }^{11}$, determinou a obrigatoriedade do fornecimento de listas telefônicas gratuitamente (art. 213) e determina ser obrigatório e gratuito o fornecimento de listas telefônicas aos assinantes do serviço. Ocorre que a maioria das empresas telefônicas, a exemplo da ECT, parou de publicar a lista impressa e, em seu lugar, criou acessos pela internet pelos quais o cidadão deve pesquisar um a um os dados desejados. Os sistemas oferecidos para consulta, não concedem acesso a lista, e sim à dados isolados. Entretanto, há inúmeras ações na justiça ${ }^{\text {vi }}$ e denúncias nos órgãos de defesa do consumidor, e em consequência dessas ações, algumas empresas telefônicas já providenciam a impressão da lista, aos que solicitam pelos sites, sem custos ao cidadão.

Verificamos que serviços telefônicos e postais, que ofereciam gratuitamente aos seus usuários a lista completa impressa, com o advento do documento eletrônico e da internet, retiraram esse acesso aos cidadãos. O que era uma informação pública e gratuita, sem nenhuma modificação na legislação, passou a ser um produto comercializado.

\section{A análise do Acesso ao CEP pela CGU e STF}

Após a implantação da Lei de Acesso à Informação (LAI) no Brasil, a ECT recebeu o Pedido de Informação - NUP 99923.001172/2012-06, com o seguinte pedido: "Muitos sistemas necessitam acesso à base de dados do CEP, porém a ECT coloca barreiras técnicas e financeiras ao acesso a estes dados. A falta de acesso livre a esta base de dados causa a disseminação de cópias desatualizadas, o que prejudica não apenas os usuários, mas a própria ECT, uma vez que ela é obrigada a entregar correspondência mesmo com o CEP informado incorretamente. Portanto é do interesse do público e da própria ECT que estes dados sejam oferecidos de forma livre através de uma API (interface de programação) aberta e de fácil utilização”

A ECT respondeu com o tipo de resposta "Acesso negado - Informação sigilosa de acordo com legislação específica" informando que o e-DNE é um produto comercializado pela ECT por meio da Correios Online e que "a informação de forma individualizada encontra-se disponível, por meio do Busca CEP, no site www. correios.com.br" ${ }^{6}$, pelo qual qualquer cidadão pode consultar gratuitamente o CEP. A ECT alegou ainda, que o e-DNE é considerado obra intelectual nova e original, nos termos da Lei. 9.610/1998 (Lei de Direitos Autorais) ${ }^{12}$, sob titularidade da empresa e que "depositou e é legitima titular perante o Instituto Nacional de Propriedade Industrial (INPI) do pedido de Patente de Invenção [...], titulado 'Diretório Nacional de Endereços (DNE)”’2 e perante o German Patent Applicatations, depositou e é legitima titular da extensão da patente de invenção. $O$ cidadão registrou recurso em função da negativa de acesso onde alegou que não pedia o e-DNE e sim a base de dados, onde afirma que "o e-DNE não corresponde ao pedido original de acesso à uma API aberta e gratuita” ${ }^{2}$ e mais uma vez trazendo para sua defesa artigos da LAI que garantem o acesso

vi O site JusBras organiza a informação jurídica no país e possibilita localizar os processos em tramitação na justiça brasileira. Pesquisando sobre o tema "listas telefônicas gratuitas" é possível identificar os processos sobre o tema, <http://www.jusbrasil.com. br/topicos/26876393/fornecimento-de-lista-telefonica-impressa> 
em transparência ativa, por meio eletrônico e gratuito aos dados produzidos por uma instituição pública. O pedido chegou a $3^{\mathrm{a}}$ instância recursal, a CGU, que no parecer objeto do Despacho $n^{0}$ 4.775, de 20/06/2013, do Ouvidor-Geral da União (OGU), assinado também por dois Analistas de Finanças e Controle da CGU, faz uma desconstrução da resposta da ECT. Nele os técnicos analisam a Lei de Patentes e argumentam que o conteúdo de banco de dados não é objeto patenteável e, caso tal ocorra, "poderá vir a ser objeto de declaração de nulidade, por força do art. 46 da Lei 9.279/199684”2. Destacam ainda que o depósito de pedido de patente não gera senão a expectativa de um direito, a ser ou não confirmado mediante a outorga da carta patente, e não tem o poder de configurar hipótese legal de sigilo. O despacho faz ainda uma análise histórica do CEP quanto à sua natureza pública, quando foi desenvolvido em substituição às Zonas Postais ou Zonas de Correio, criadas pelo DCT, e com a publicação do Decreto-Lei 509/196985, todo capital proveniente da União, que estava a serviço, ou à disposição do DCT, passou à ECT e que ao longo destas quase cinco décadas o CEP passou a ser usado em todo território nacional, estando em placas sinalizadoras de logradouros na maioria dos munícipios brasileiros. A CGU questiona o fato de a ECT nunca ter impedido que estes fossem divulgados. Na avaliação da CGU tal comportamento da empresa é de que a informação era de interesse público e devia ser divulgada. Destacaram ainda, o fato da lista (em papel), com o registro agregado dos CEP, ter sido disponibilizada em todas agências da ECT e que ficava ao alcance do cidadão. A CGU analisa ainda os artigos da Constituição Federal (CF) de 1988 que determinam ser de competência da União manter o serviço postal e o correio aéreo nacional. "Em outras palavras, situa-se o desenvolvimento e atribuição de indexação a logradouros verdadeiro serviço público uti universi, que, apesar de servir ao bom desempenho da atividade econômica, com ela não se confunde. Entretanto, a CGU entende que somente pode dar provimento ao objeto existente e que por solicitar providências, a solicitação está fora do escopo do juízo recursal. " Assim, não deu provimento e sugeriu a ECT que "tome as medidas adequadas para, em tempo futuro, disponibilizar a informação solicitada em transparência ativa, conforme determina o art. $8^{\circ}$ da Lei 12.527/2011"2.

Em 2013, mais um dos vários pedidos recebidos na empresa solicitando a base de dados do CEP seguiu para recurso de $3^{\text {a }}$ Instancia, o NUP $99923.000436 / 2013-87^{\text {vii }}$. No recurso o cidadão argumentou que a empresa não poderia comercializar uma informação pública, exemplificando a hipótese de o TCU comercializar seus pareceres. A CGU frente ao dilema identificado, encaminhou consulta à Comissão Mista de Reavaliação de Informações (CMRI) viii, apresentando os oito argumentos da empresa. "15. Oito são os argumentos dos quais faz uso a Empresa Brasileira de Correios e Telégrafos para negar acesso à base de dados de Códigos de Endereçamento Postal: (1) o direito de exploração mercantil da informação que lhe conferiria a Lei Postal, (2) o direito de propriedade intelectual que lhe conferiria o depósito de pedido de patente de invenção junto ao INPI, registrado sob número PI 0.204.305-0, (3) o sigilo comercial, (4) o caráter não público da informação solicitada, (5) o risco à competitividade decorrente da publicização, (6) o art. 13, III do Decreto 7.724/2012, considerando não atendível o pedido diante da necessidade de trabalho adicional de consolidação de dados e informações. (7) adicionalmente, faz menção ao art. $5^{0} \S 1^{0}$ do Decreto 7.724/2012 para inserir o debate na proteção especial às informações das empresas públicas e (8) alude a que o caráter geral da Lei de Acesso à Informação afastaria a sua aplicabilidade em face da especificidade da matéria tratada pela Lei Postal. "13.

A CGU na consulta ressalta ser o CEP imprescindível à manutenção do serviço postal no Brasil, e assim, indispensável ao correto desempenho de competência constitucionalmente atribuída à União (inciso X, art. 21 da CF) de manutenção do serviço postal, e considera pouco defensável a tese de que o acesso à informação represente risco de competitividade ou governança à ECT: "49. O dilema que o dispositivo nos impõe, ao considerarmos pública a informação relativa ao Código de Endereçamento Postal, diz respeito ao

vii Disponível em <http://www.acessoainformacao.gov.br/precedentes/ECT/99923000436201387.pdf>

viii Comissão Mista de Reavaliação de Informações, criada pelo $\S 1^{\circ}$ do Art. 35 da Lei 12.527/2011 última instância recursal no cumprimento da Lei de Acesso à Informação no Brasil, composta por representantes dos Ministros de Estado. 
conflito entre a vedação de cobrança por disponibilização de informação pública e uma herança pretérita à nova legislação, que da informação pública fez produto comercializado. Note-se que não se divisa proibição expressa à venda do produto e-DNE, porquanto se presuma que nele haja valor agregado em forma de suporte ou leiaute de base de dados, justamente aquilo que a legislação permite a cobrança por reprodução, salvo hipótese excepcionalmente prevista na Lei 7.115/1983. " ${ }^{13}$ [...] e “6o. Pelo exposto, delimita-se a antinomia como conflito real entre o art. $5^{\circ}$, inciso XXXIII da Constituição, combinado com o art. 12 da Lei 12.527/2011 e o art. $5^{\circ}$, caput e incisos XXII e XXVII e art. 173, $\S 1^{\circ}$, II da Constituição Federal, combinados com o art.

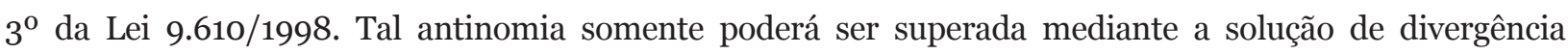
administrativa, nos termos do art. 10, III do Regimento da Comissão Mista de Reavaliação de Informações, acerca da natureza da informação solicitada, visto que, hipóteses auto excludentes, se de natureza pública, não terá natureza patrimonial, e se de natureza patrimonial, não terá natureza pública. 61. Diante de tal fato, sugere-se a subida do presente à Comissão Mista de Reavaliação de Informações, para que, nos termos do art. 10, III, da Resolução $\mathrm{n}^{0} 1$ da CMRI e no exercício da competência que lhe é atribuída pelo art. 47, V do Decreto 7.724/2012, se pronuncie sobre a natureza da informação, nos termos reproduzidos no § supra e referende, se assim decidir, o caráter público da informação solicitada ou, de forma diversa, seu caráter patrimonial. "13.

A resposta da CMRI à CGU, em 3 de outubro de 2013, foi “[...] para essa Controladoria-Geral da UniãoCGU proceda a análise do mesmo à luz da Lei Postal no 6.538/1978. [...]”13. A CGU considerou que a resposta oferecida pela CMRI não respondeu à questão de repercussão geral e interpretou que a CMRI considerou a prevalência do art.15 da Lei 6.538/1978 (Lei Postal) sobre o art. 12 da Lei 12.527/2012 (LAI), admitindo assim, que possa uma informação pública ser objeto de comercialização, e que sua natureza patrimonial decorre da possibilidade de comercialização, e não de pré-existência de direito de propriedade que sobre ela exista na esfera pública. O parecer final entende ainda que foi apenas uma consulta e que não seria empecilho para o requerente apresentar recurso à CMRI. Entretanto, nenhum dos pedidos sobre acesso a base do CEP seguiu à CMRI, até a conclusão de nossa pesquisa.

Em artigo publicado na internet intitulado "Por que o CEP deve ser tratado como informação pública? "14, as decisões da ECT e CGU, são objeto de crítica pública. O questionamento no artigo é de como uma base pública, de interesse público, pode permanecer fechada, sendo acessível apenas a quem tem dinheiro. Este é um exemplo onde o caráter híbrido da empresa, no caso, o lado empresarial, sobrepõe-se ao lado público na disponibilização da informação pública.

\section{O CEP e Dados Abertos}

A Open Knowledge Internacional publica o Índice Global de Dados Abertos ${ }^{15}$ e acompanha a transparência pública no Brasil e no Mundo. No ano de 2015 a publicação do ranking dos países apresentou o Brasil na posição de $12^{\circ}$. Esta posição após a implantação da LAI, em 2012, poderia ser melhor. Segundo conclusões da organização "os dados das empresas e de códigos postais (CEP) ainda precisam melhorar na comparação"ix. O Código Postal já está disponível no Reino Unido, Dinamarca, Colômbia, Uruguai, México, Finlândia, França, Estados Unidos etc. No Ranking de Dados Abertos ${ }^{\mathrm{x}}$, na coluna Location, é possível verificar o status de liberação das informações de 122 países no mundo. Neste item são esperados como Dados Abertos: um banco de dados de códigos postais (CEP) e os locais espaciais correspondentes em termos de latitude e longitude (ou coordenadas semelhantes em um sistema de coordenadas publicado publicamente) - endereços, e que os dados estejam disponíveis para todo o país. Em 2015, o ranking indicava uma cor azul, como identificação de que a informação estava "pouco clara".

ix Conclusões sobre a publicação do Índice <http://br.okfn.org/2015/12/02/open-knowledge-internacional-publica-o-indice-globalde-dados-abertos-2015-mapeando-o-estado-dos-dados-abertos-ao-redor-do-mundo/>

x Disponível em <http://index.okfn.org/place/> 
Em nota aos usuários a Open Knowledge Internacional informa que a metodologia utilizada no Global Open Data Index foi alterada ao longo do tempo e que houve uma significativa mudança entre 2015 e 2016, e por esse motivo, os resultados disponíveis não são diretamente comparáveis ao longo do tempo. A situação do Brasil mudou de 2015 para 2017, passando para o $8^{\circ}$ lugar no ranking (Figura 1), empatado com a Nova Zelândia. Entretanto, no que diz respeito ao item Location este passou a estar vermelho. Este dado é analisado segundo os seguintes critérios: licenciamento aberto; formato aberto e legível; download automático; atualização do dado; disponibilidade pública e disponibilidade gratuita. Em todos estes quesitos o resultado do Brasil é negativo: não disponível.

Figura 1 - Ranking Dados Abertos 2017

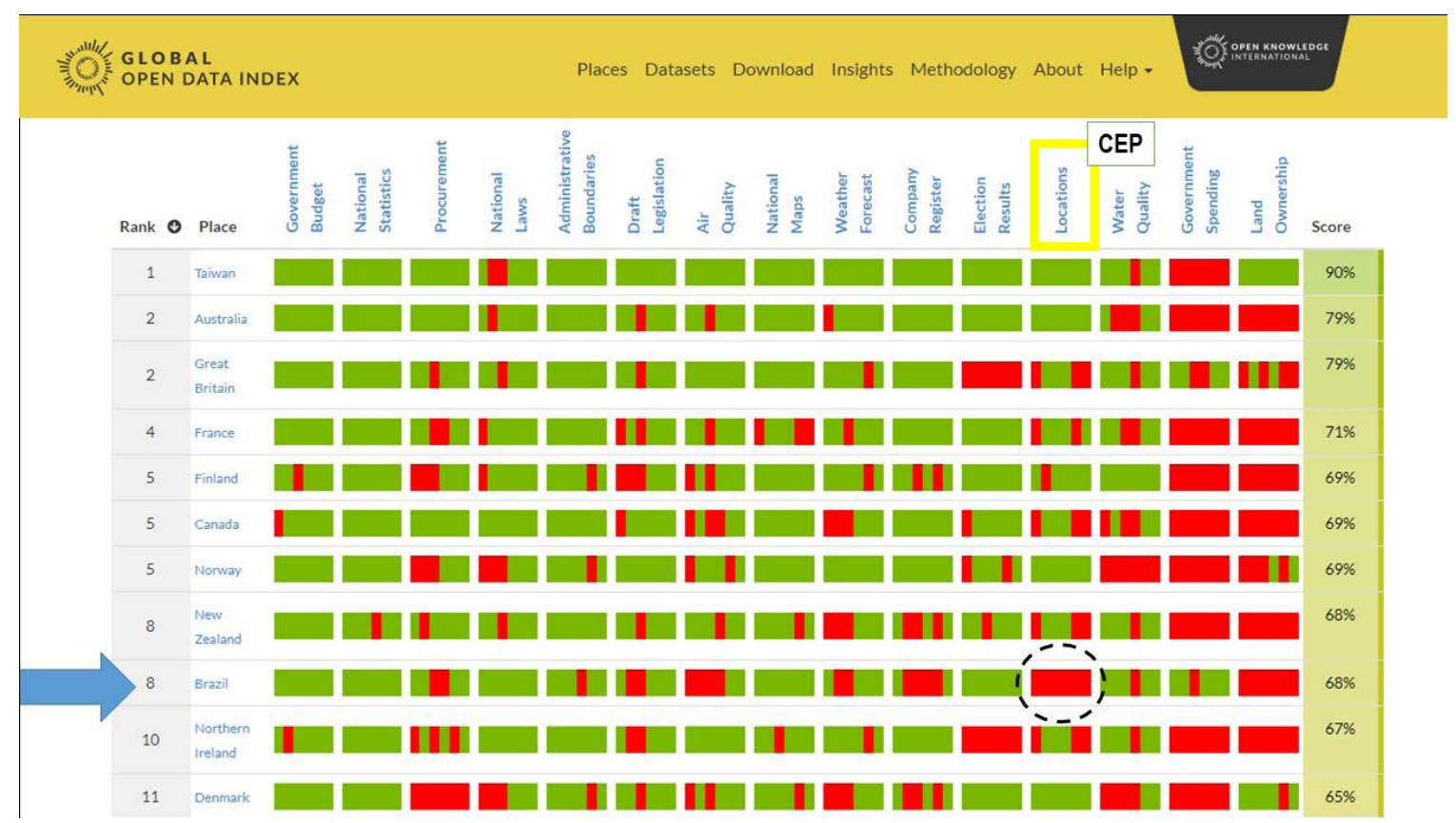

Fonte: elaborado pela autora com base no Global Open Data Index ${ }^{\mathrm{xi}}$

Com relação ao ranking na Figura 1, verificamos como a não liberação do CEP, enquanto Dados Abertos, interfere na posição do Brasil na classificação mundial, junto ao item Propriedade da Terra (Land Ownership).

A compreensão da transparência das informações públicas vem se ampliando a cada dia na sociedade brasileira. Entretanto, o que pouco se discute é o conceito de informação pública ${ }^{3}$. Segundo Zepeda ${ }^{16} \mathrm{o}$ conceito político de privacidade - o que é próprio do privado - significa "exclusão" ou "separação". O autor destaca que com o ascenso dos sistemas liberais durante o século XVII, o privado veio a significar tudo aquilo que não estava envolvido, ou definido pela esfera do aparato governamental. Dessa forma o privado chegou a ser definido em oposição às tarefas governamentais. Zepeda ${ }^{16}$ apresenta ainda que o sentido do privado supõe também que um conjunto de privados dão lugar a outra dimensão do público, que denominamos "o público", que não é governamental. O autor exemplifica no sentido que está presente na noção de "opinião pública", concebida como opinião que agrega os agentes privados, sem que essa condição de publicidade adquirida, nunca a torna opinião do Estado. Outro exemplo é na língua inglesa que "the public" equivale ao povo em geral. O autor reforça a necessidade de distinguir entre "o público", a soma de privados, opinião pública não governamental, e "no público", relativo ao Estado e suas normas, instituições e ações específicas. Essa distinção é extremamente importante na implantação dos Dados Abertos no Brasil quando órgãos governamentais se apropriam de uma informação que pertence a população desde sempre.

xi O mapa deve ser lido com as variações das cores onde o vermelho representa "não disponível" e o verde "disponível". No site é possível acessar cada item e as análises e avaliações do ranking. 
Vários autores atestam que o Brasil, a partir dos anos 2000, avançou na adoção de medidas concretas à transparência pública. A CGU na publicação sobre Acesso à Informação Pública, introduzindo a então recente lei de acesso aprovada, afirma que o Brasil já era referência em matéria de divulgação espontânea de informações governamentais: "O Portal da Transparência do Governo Federal, criado e administrado pela CGU, já foi várias vezes premiado, nacional e internacionalmente, sendo considerado um dos mais completos e detalhados sites de transparência do mundo"17. O mapa de dados abertos é bem ilustrativo ao mostrar a coluna de Despesas Governamentais em que pouquíssimos países dão transparência a esta informação, e o Brasil está nesta seleta lista de países.

\section{Considerações Finais}

No Brasil, Política de Dados Abertos no poder Executivo Federal, foi instituída pelo Decreto $\mathrm{n}^{0} 8.777$ de 11 de maio de 2016, com o objetivo, entre outros, de promover a publicação de dados contidos em bases de dados de órgãos e entidades da administração pública federal direta, autárquica e fundacional sob a forma de dados abertos e informações acessíveis ao público, visando o aprimoramento da cultura de transparência pública. Como a ECT é da administração indireta, esta normativa não é autoaplicável.

A ECT ao prestar um serviço de levar de um ou vários remetentes, à um ou vários destinatários um documento, uma carta, um telegrama, um objeto, está exercendo o papel de viabilização do acesso à informação para a sociedade. A importância desta atividade é tanta que em momentos históricos, em que a democracia é suprimida, ela é alvo de controle e censura ${ }^{5}$.

Mesmo com as novas tecnologias, como a internet, ainda existem milhões de pessoas que utilizam o serviço postal para troca de informações. No Brasil, um contingente de $42 \%$ dos brasileiros não tem acesso à internet, em várias cidades e vilarejos, e é o carteiro que faz o transporte da informação, utilizando todos os meios possíveis (caminhando, de bicicleta, de moto ou de carro). Neste sentido o debate sobre o CEP se apresenta com destaque pela importância que tem para a sociedade brasileira. Qualquer cidadão, pessoa física ou jurídica, em qualquer país do mundo, para postar e receber, qualquer carta ou correspondência ou mesmo uma encomenda, sabe que é indispensável informar o código postal correto e atualizado para o bom cumprimento do serviço postal. Serviço este que está presente na Constituição Federal como sendo de competência da União a sua manutenção. A posição do Brasil no ranking de Dados Abertos mostra o quanto a não disponibilização desta informação reflete na sua classificação (Figura 1).

O CEP é um mecanismo de organização espacial, necessário para projetos de georeferenciamento e para o desenvolvimento das pequenas e médias empresas. A CGU reconhece que é uma informação pública, e não propriedade comercial da ECT, mas que continua sendo negada uma vez que a CMRI considerou a observância da Lei Postal sobre a Lei de Acesso à Informação. A sociedade brasileira já conviveu com o livre acesso a todos os CEPs consultando às listas impressas, em arquivo txt até os anos 2000, e em várias cidades estão reproduzidos nas placas de sinalização de cada rua. Ou seja, é uma informação pública, mas que a base de dados é negada ao cidadão.

O CEP constituiu-se, no Brasil, um dos poucos casos em que verificamos que o advento da informação eletrônica ao invés de ampliar o acesso à informação aos cidadãos, trouxe limitação, e até mesmo cerceamento, ao priorizar a atividade econômica sobre a prestação de serviço público.

\section{Referências}

1. BRASIL. ECT. CEP-Código de Endereçamento Postal. Disponível em <https://www.correios.com.br/paravoce/correios-de-a-a-z/cep-codigo-de-enderecamento-postal>. Acesso em 30.jun.2017.

2. BRASIL. Controladoria Geral da União. DESPACHO no 4775 de 20/06/2013. Referência: 99923.001172/2012-06 Assunto: Recurso interposto por cidadão à CGU contra decisão denegatória de acesso à informação, com fundamento no art. 23 do Decreto no 7.724, de 16 de maio de 2012. 
Brasília, DF, 20.jun.2013, p.4. Disponível em <http://www.acessoainformacao.gov.br/precedentes/ ECT/99923001172201206.pdf>. Acesso em 30.jun.2017.

3. BRASIL. ECT. Sobre Correios, A empresa, História. História Postal. Disponível em < http://www.correios. com.br/sobre-correios/a-empresa/historia> . Acesso em 30.jun.2017.

4. BRASIL. Supremo Tribunal Federal. Recurso extraordinário n. 589.998-PI. Relator: Min. Ricardo Lewandowski. Data de publicação: DJE 12/09/2013 - Ata n. 131/2013. DJE n. 179. Disponível em: $<$ http://redir.stf.jus.br/paginadorpub/paginador.jsp?docTP=TP\&docID=4499353 > Acesso em: 30.jun.2017.

5. RIBEIRO, Ana Maria de A. Organização e acesso à informação na Empresa Brasileira de Correios e Telégrafos após promulgação da Lei de Acesso à Informação. [Dissertação]. Distrito Federal, Brasília: Universidade de Brasília; 2016, p. 136/7, p.104, p.51/52. Disponível em: <http://repositorio.unb.br/ handle/10482/2292>1. Acesso em 30.jun.2017.

6. BRASIL. ECT. DNE-Diretório Nacional de Endereços. Disponível em < $\quad$ https://www.correios.com.br/paravoce/correios-de-a-a-z/dne>. Acesso em 20.jan.2017.

7. CRESWELL, John W. Projeto de pesquisa: métodos qualitativo, quantitativo e misto. 3. ed. Porto Alegre, RS: Artmed, 2010. P.31.

8. BRASIL. Decreto-Lei no 509, de 20 de março de 1969. Dispõe sobre a transformação do Departamento dos Correios e Telégrafos em empresa pública, e dá outras providências. Diário Oficial [da] União, Brasília, DF, de 21.mar.1969 e retificado em 25.mar.1969 http://www.planalto.gov.br/ccivil 03/decretoLei/Del0509.htm>. Acesso em 30.jun.2017.

9. TEIXEIRA, Tadeu G. Os correios em transformação: reestruturação, organização do trabalho e políticas de gestão do trabalho (1994-2011). Tese (doutorado em ciências sociais) - Instituto de Filosofia e Ciências Humanas, Universidade Estadual de Campinas, 2013. Disponível em Biblioteca Digital da Unicamp <http://repositorio.unicamp.br/handle/REPOSIP/280162>. Acesso em 30.jun.2017.

10. BRASIL. Lei no 6.538, de 22 de junho de 1978. Lei Postal. Diário Oficial da União, Brasília, DF, de 23. jun. 1978.

11. BRASIL. Lei no 9.472, de 16 de julho de 1997. Dispõe sobre a organização dos serviços de telecomunicações, a criação e funcionamento de um órgão regulador e outros aspectos institucionais, nos termos da Emenda Constitucional no 8, de 1995. Diário Oficial da União, Brasília, DF, de 17.jul.1997.

12. BRASIL. Lei no 9.610/1998. Altera, atualiza e consolida a legislação sobre direitos autorais e dá outras providências. Diário Oficial da União, Brasília, DF, de 20.fev.1998. Disponível em <http://www.planalto. gov.br/ccivil 03/leis/L9610.htm>. Acesso em 16.jul.2017.

13. BRASIL. Controladoria Geral da União. PARECER no 3012 de 21/11/2013. Referência: 99923.000436/2013-87 Assunto: Recurso à CGU contra acesso decisão denegatória de acesso à informação. Brasília, DF, 21.nov.2013, p.14 -18/19. Disponível em <http://www.acessoainformacao.gov. br/assuntos/recursos/recursos-a-cgu/arquivos/ministerio-das-comunicacoes/ect/pa30122013.pdf/view>. Acesso em 30.jun.2017.

14. SANTINI, Daniel. Por que o CEP deve ser tratado como informação pública? Código Urbano. Publicado em 12.mar.2015. Disponível em < http://codigourbano.org/por-que-o-cep-deve-ser-tratado-comoinformacao-publica/>. Acesso em 30.jun.2017.

15. OPEN KNOWLEDGE BRASIL. Global Open Data Index 2015. Disponível em < http://index.okfn.org/ place/>. Acesso em 30.jun.2017.

16. ZEPEDA, Jesús Rodríguez. Estado y transparência: um paseo por la filosofia política. Cuadernos de transparência no 4. Mexico: Instituto Federal de Acesso a la Infomación y Protección de Datos (IFAI), Octava impresion, septiembre 2012, p. 18 - 29. Disponível em <http://inicio.inai.org.mx/Publicaciones/ Cuadernillo\%2004\%20B.pdf>. Acesso em 30.jun.2017.

17. BRASIL. Controladoria Geral da União. Cartilha de Acesso a Informação. Brasília, DF: 2011, p.3. Disponível em <http://www.acessoainformacao.gov.br/central-de-conteudo/publicacoes/arquivos/ cartilhaacessoainformacao.pdf>. Acesso em 30.jun.2017. 